\title{
Sweet syndrome revealing a leukemia
}

\section{Siham Belmourida, Mehdi Khallayoune, Hind Palamino, Mariame Meziane, Nadia Ismaili, Laila Benzekri, Badr Hassam, Karima Senouci}

\author{
Department of Dermatology-Venerology, Mohammed V University, Ibn Sina Hospital, Rabat, Morroco
}

Corresponding author: Dr. Siham Belmourida, E-mail: belmouridasiham2017@gmail.com

Sir,

Sweet's syndrome (SS) is a rare entity that is part of neutrophilic dermatoses. It mainly affects the adult and it's rare in children [1].

We report the case of acute lymphoblastic leukemia revealed by (SS) in a 9-year-old child.

A 9-year-old child, with no particular ATCD, consulted for febrile eruption of sudden onset, arthralgia, and alteration of the general state. The clinical examination revealed an asthenic child, febrile at 39.5 with the presence of hot and painful maculopapular erythematous plaques in the face, back, thorax and upper limbs (Figs. la - lc). There was no hepatosplenomegaly or palpable lymphadenopathy, and the rest of the somatic examination was unremarkable.

The blood count revealed hyperleucocytosis at 40960/ $\mathrm{mm}^{3}$ predominantly lymphocytic, normochromic normocytic non-regenerative anemia at $9 \mathrm{~g} / \mathrm{dL}$, thrombocytopenia at $38000 / \mathrm{mm}^{3}$.

The study of myelogram concluded to acute lymphoid leukemia. The biological inflammatory syndrome was frank, with an accelerated sedimentation rate at $60 \mathrm{~mm}$ in the first hour and a $\mathrm{C}$ reactive protein at $97 \mathrm{mg} / \mathrm{L}$. The cutaneous biopsy showed edema of the dermis with inflammatory infiltrate made of lymphoplasmocytic cells (Figs. 2a and 2b) the diagnosis of (SS) associated with leukemia was retained.

(SS) is usually reported in adults with a female predominance. Pediatric cases are rare and no predominance of sex has been described $[1,2]$. The pathogenesis of (SS) remains unknown. A hypersensitivity reaction to a bacterial, viral, tumor or drug antigen has been suggested [3]. The clinical presentation is essentially made of an infectious syndrome associated with painful erythematous skin lesions. General symptoms can also be observed. As in adult, pediatric (SS) can be idiopathic or associated with neoplastic, inflammatory, infectious disease or drug-induced [1-3].

In our patient the diagnosis was retained in front of the typical clinical presentation, the biological inflammatory syndrome, the cutaneous biopsy made not objectifying vasculitis and the fast remission under corticotherapy.
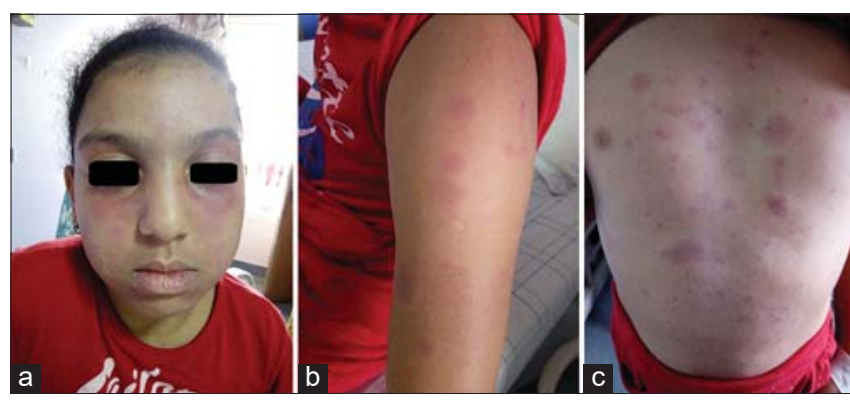

Figure 1: (a-c) Clinical photos showing inflammatory erythematonodular lesions of the upper body typical of Sweet's syndroma.

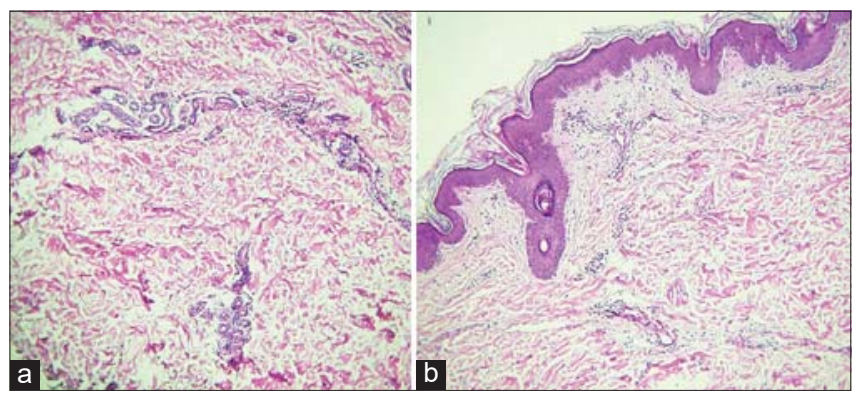

Figure 2: ( $a$ and b) Skin biopsy objecting to dermal edema with moderate inflammatory infiltrat made of lympho-plasmocytes.

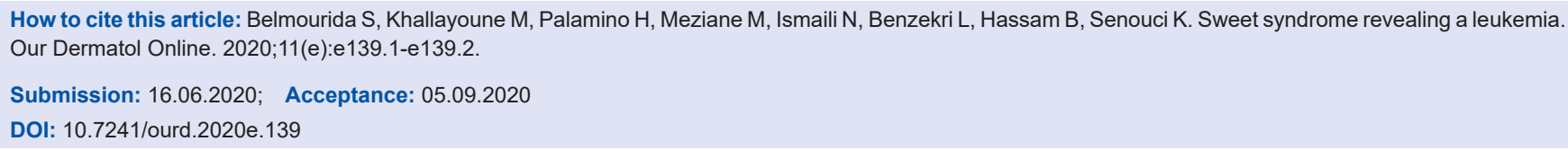


The diagnosis of (SS) must be the subject of a thorough etiological investigation and prolonged surveillance is necessary to diagnose a possible associated pathology.

\section{Consent}

The examination of the patient was conducted according to the principles of the Declaration of Helsinki.

The authors certify that they have obtained all appropriate patient consent forms, in which the patients have given consent for images and other clinical information to be included in the journal. The patients understand that their names and initials will not be published and due effort will be made to conceal their identity, but that anonymity cannot be guaranteed.

\section{REFERENCES}

1. Selvakumar Monisha D, Narasappa Raghavendra B, Kumar Patra A. A case of infantile Sweet's syndrome. Our Dermatol Online. 2020;11:143-5.

2. Pai K, Pai S, Rao R, Shetty S. Photodistributed Acute febrile neutrophilic dermatosis: a case report. Our Dermatol Online. 2014;5:416-8.

3. Stevens GJ, Yutronic HJ, Pizarro OJ, Velozo PL. Sweet syndrome in pediatrics. A case report. Rev Chil Pediatr. 2018;89:511-5.

Copyright by Siham Belmourida, et al. This is an open-access article distributed under the terms of the Creative Commons Attribution License, which permits unrestricted use, distribution, and reproduction in any medium, provided the original author and source are credited.

Source of Support: Nil, Conflict of Interest: None declared. 